\title{
Characterization by Proper-Orthogonal-Decomposition of Flow Field around Bridge Slotted Decks
}

\author{
W. Zhang ${ }^{1 *}$, Y. J. Ge ${ }^{1}$, T. C. Li11 ${ }^{1}$ \\ ${ }^{1}$ State Key Laboratory for Disaster Reduction in Civil Engincering, Tongji University, Shanghai \\ 200092, China \\ Email: samch@mail.tongji.edu.cn
}

\begin{abstract}
For the limitations of the research methods, emphasis has always been put on the dynamics of the bridge sections with no concern about the flow structure around the decks, when carrying the research of the mechanism of wind-induced vibrations. The emergence of PIV (particle image velocimetry) makes it possible to analyze the flow structures. In order to inspect the relationship between the dynamics of decks and the flow structures around the decks, the static force coefficients of the bridge slotted decks and the velocity maps are marked and analyzed using numerical wind tunnel tests. Snapshot POD method is carricd out to analyze the flow structures around the decks to find the dominant vortices in the flow filed. The fluctuating velocity maps are reconstructed using the first several modes with most of the energy contained. The research shows that in the flow field around the decks there are some periodic moving vortices. Relationship is found between the rule of the kinemics of the vortices and the static force coefficients of the decks. The research in this paper will guarantee the theoretical basis for investigating the micro mechanism of wind induced vibrations of bridges using the method of PIV.
\end{abstract}

Key words: Proper-orthogonal-decomposition, static force coefficients, bridge slotted decks, wake flow

\section{REFERENCES}

1. Fung YC. An Introduction to the Theory of Aeroelasticity. New York: Dover Publication, 1993

2. Walshe DE, Twidle GG, Brown W.C. Static and dynamic measurements on a modal of a slender bridge with perforated deck. In: International Conference on the Behaviour of Slender Structures. The City University, London, England. 1997

3. Adrian RJ, Christensen KT, Liu ZC. Analysis and interpretation of instantaneous turbulent velocity ficlds. Experiments in Fluids, 2000;29(3):275-290

4. Berkooz G, Holmes P, Lumley J. The proper orthogonal decompostion in the analysis of turbulent flows. Annual Review of Fluid Mechanics, 1993;25:539-575

5. Santa Cruz A., et al. Characterization by proper-orthogonal-decompostion of the passive controlled wake flow downsteam of a half cylinder. Experiments in Fluids, 2005;39(4):730 